\title{
Exame histopatológico do end ométrio da égua após infecções experimentais repetidas e cinco diferentes tratamentos: aspectos inflamatórios
}

\author{
Histopathological examination of mare's endometrium after repetitive experimental \\ infections and five different treatments: inflammatory aspects
}

\section{Andrea Keller ${ }^{1}$, Adriana Pires Neves ${ }^{1}$, Heike Aupperle ${ }^{2}$, Katja Steiger ${ }^{2}$, Heinz-Adolph Schoon ${ }^{2}$, Erich $\mathrm{Klug}^{3}$, Ricardo Macedo Gregory ${ }^{1} \&$ Rodrigo Costa Mattos ${ }^{1}$}

\begin{abstract}
RESUMO
A endometrite é uma importante causa de subfertilidade na égua. O objetivo deste trabalho foi verificar o efeito de diferentes tratamentos sobre o endométrio de éguas infectadas experimentalmente. Foram utilizadas vinte éguas resistentes, com histórico reprodutivo desconhecido, e cinco éguas susceptíveis, com histórico de endometrites recorrentes e subfertilidade. Após o primeiro exame histopatológico os ciclos foram sincronizados com prostaglandina. Na fase estral, as éguas foram infectadas com 1 x $10^{9}$ Streptococcus equi. Vinte e quatro horas após a infecção, os animais eram submetidos aos exames clínico, bacteriológico e citológico. Constatada a presença de sinais clínicos de endometrite, os grupos de éguas foram distribuídos entre cinco diferentes tratamentos: leucócitos frescos, leucócitos congelados, leucócitos lisados, Interleucina-8 e grupo controle. As éguas foram tratadas diariamente, por no máximo, quatro dias, ou até que o exame bacteriológico não evidenciasse o crescimento de Streptococcus. No quinto dia, as éguas eram então submetidas a novo exame histopatológico e, no sétimo, dia todas as éguas eram tratadas com penicilina, independentemente de terem eliminado a infecção ou não. Sete dias após, as éguas eram novamente submetidas a exame histopatológico e sincronizadas para realizar uma nova infecção e novo tratamento. As biópsias foram avaliadas quanto à endometrite. Conclui-se que éguas susceptíveis à endometrite, com presença de Streptococcus no útero, não apresentam neutrofilia após cinco dias de infecção. Provavelmente o menor tempo de eliminação bacteriana observado nos tratamentos com leucócitos frescos e congelados deva-se a outros fatores que não o efeito quimioatraente dessas células.
\end{abstract}

Descritores: égua, endometrite, plasma, leucócitos, biópsia endometrial.

\begin{abstract}
Endometritis is an important cause of subfertility in the mare. The aim of this study was to determine the effect of different treatments on the endometrium of mares experimentally infected. Twenty resistant mares, with unknown reproductive history, and five susceptible mares, with history of recurrent endometritis and subfertility, were used. Cycles were synchronized with prostaglandin after the first histopathological examination. During estrus, mares were infected with $1 \times 10^{9}$ Streptococcus equi. Twenty four hours after the inoculation, clinical, bacteriological and cytological examinations were performed. When endometritis clinical signs were detected, the groups of mares were distributed into five different treatments: fresh leukocytes, frozen leucocytes, lysed leucocytes, Interleukin-8 and control group. Mares were treated on a daily basis for no more than four days, or until there was no Streptococcus growth in bacteriological examination. On the fifth day, mares were submitted to a new histopathological examination and, on the seventh day, all the mares were treated with penicilin, independently of having eliminated infection, or not. Seven days after, mares were submitted to a new histopathological examination and synchronized in order to proceed to a new infection and a new treatment. Biopsies were evaluated for endometritis. It was concluded that susceptible mares showing Streptococcus in uterus do not present with neutrophile growth five days after infection. The shorter time required for bacterial elimination when fresh and frozen leukocytes were used is probably due to other factors than leukocyte chemoattractive effect.
\end{abstract}

Key words: mare, endometritis, plasma, leukocytes, endometrial biopsy.

${ }^{1}$ Reprolab, Faculdade de Veterinária, Universidade Federal do Rio Grande do Sul (UFRGS), Porto Alegre, RS - Brasil. ${ }^{2}$ Instituto de Patologia, Faculdade de Veterinária, Universidade de Leipzig. ${ }^{3}$ Clínica para Eqüinos, Escola Superior de Veterinária de Hannover. CORRESPONDÊNCIA: R.C. Mattos [rcmattos@ufrgs.br ; FAX 3316 7305]. 


\section{INTRODUÇÃO}

A endometrite é uma importante causa de subfertilidade na égua. É bem documentada a infecção bacteriana transitória que ocorre durante a cobertura ou inseminação, mesmo que todas as medidas de higiene tenham sido tomadas. $\mathrm{O}$ quadro é passageiro em éguas sadias, denominadas resistentes, que são capazes de eliminar agentes bacterianos e produtos inflamatórios do lúmen uterino em poucas horas ou dias [23]. As éguas que falham em resolver esta endometrite aguda e permanecem continuamente infectadas são denominadas susceptíveis $[6,8,10]$.

Estas éguas demonstram atividade miometrial diminuída [21], permitindo a aderência das bactérias ao endométrio pela demora na limpeza de subprodutos da inflamação [12]. Estudos feitos em câmaras quimiotáticas constataram que neutrófilos polimorfonucleares das secreções uterinas de éguas susceptíveis têm menor capacidade de migrar e fagocitar bactérias, quando comparados os de éguas resistentes [13,24]. Esta fagocitose deficiente seria resultado da influência negativa das secreções uterinas de éguas susceptíveis, que seriam mais pobres em opsoninas que as secreções uterinas das éguas resistentes [22].

A biópsia endometrial é um procedimento confiável e seguro para o diagnóstico e prognóstico de distúrbios endometriais relacionados à infertilidade na égua [20]. A técnica é útil para detectar alterações associadas com baixa fertilidade, não facilmente diagnosticadas por outros métodos, e para monitoração da resposta a uma terapia uterina específica [4].

O objetivo deste trabalho foi documentar o efeito de diferentes tratamentos sobre o endométrio, após infecções experimentais, através do exame histopatológico do material obtido por biópsia.

\section{MATERIAIS E MÉTODOS}

Foram utilizadas vinte éguas resistentes e cinco éguas susceptíveis, mantidas a campo num sistema extensivo de exploração. As 20 éguas, com histórico reprodutivo desconhecido, foram classificadas como resistentes durante o experimento. As cinco éguas classificadas como susceptíveis tinham histórico de endometrites recorrentes e subfertilidade e já haviam sido utilizadas em outros experimentos com infecção experimental. As éguas foram divididas em cinco gru- pos de cinco éguas. Cada grupo contava com uma égua susceptível e quatro resistentes.

\section{Tratamentos}

Foram utilizados 5 tratamentos diferentes:

- Leucócitos frescos: colhiam-se cerca de $300 \mathrm{~mL}$ de sangue da jugular da égua a ser tratada, em tubo heparinizado ${ }^{1}$. Em seguida eram adicionados $120 \mathrm{~mL}$ de solução de dextrose ${ }^{3}$ a $6 \%$, deixando-se decantar durante cerca de trinta minutos. $\mathrm{O}$ sobrenadante era, então, infundido no útero, em um volume de $120 \mathrm{~mL}$ $[14,16]$.

- Leucócitos congelados: os leucócitos foram separados e congelados em macrotubos [3]. Em cada macrotubo eram envasados $4 \mathrm{~mL}$ de leucócitos $\left(2 \times 10^{8}\right.$ leucócitos $/ \mathrm{mL}$ ) diluídos em plasma heterólogo e 5\% de DMSO. As amostras tinham, em média, $95 \%$ de vitalidade, medida por citometria de fluxo. As amostras eram descongeladas a $37^{\circ} \mathrm{C}$ e o conteúdo de um macrotubo diluído em $120 \mathrm{~mL}$ de solução salina antes de ser infundido no útero.

- Leucócitos lisados: sua preparação ocorreu da mesma forma que os leucócitos criopreservados, porém, ao ser feita a contagem e diluição das células, estas eram congeladas em um freezer a $-100^{\circ} \mathrm{C}$ sem crioprotetor, durante 24 horas, para provocar a lise das células. As amostras eram então descongeladas a $37^{\circ} \mathrm{C}$, envasadas em macrotubos e congeladas em nitrogênio líquido.

- IL-8 $8^{2}$ uma solução de interleucina foi diluída em PBS a uma concentração de $25 \mathrm{ng} / \mathrm{mL}$, envasada em macrotubos e congelada em nitrogênio líquido, sem necessidade de curva de resfriamento específica.

- Controle: consistia de solução de R3F (meio RPMI$1640^{3}$ com $3 \%$ de soro fetal bovino) envasada em macrotubos e congelada em nitrogênio líquido.

\section{Bactéria}

Foi utilizada uma cepa de Streptococcus equi subsp. zooepidemicus, originária de um animal tratado na Faculdade de Veterinária da Universidade Federal do Rio Grande do Sul. Após o isolamento, a bactéria foi repicada, cultivada por 24 horas e então acondicionada em palhetas plásticas de $0,5 \mathrm{~mL}$ e congelada em nitrogênio líquido até o momento da infecção experimental. Para a realização do experimento, uma das palhetas era descongelada em banho-maria a $37^{\circ} \mathrm{C}$ por 30 segundos. Seu conteúdo era semeado em ágar- 
sangue e incubado a $37^{\circ} \mathrm{C}$ por 24 horas. As placas eram lavadas com solução PBS e o lavado era então filtrado e ressuspendido em PBS até uma concentração final de $1 \times 10^{9} \mathrm{bact} / \mathrm{mL}$. A solução era mantida refrigerada até sua utilização.

\section{Delineamento experimental}

Foi feito um delineamento do tipo Quadrado Latino, com uma repetição, dividido em duas etapas: infecções experimentais e tratamentos. As 25 éguas foram submetidas a exame histopatológico (amostra pré-infecção) e sincronizadas com prostaglandina. No primeiro estro, com a presença de folículo dominante, as éguas foram infectadas experimentalmente com 1 x $10^{9}$ Streptococcus equi subsp. zooepidemicus, em uma suspensão de $20 \mathrm{~mL}$. Só foram infectadas éguas que não apresentavam sinais clínicos de endometrite. Constatada a presença de sinais clínicos de endometrite, os grupos de éguas foram distribuídos entre os cinco diferentes tratamentos:

T1 - Leucócitos frescos - Infusão de $120 \mathrm{~mL}$ de plasma homólogo acrescido de leucócitos frescos.

T2 - Leucócitos congelados - Infusão de $800 \times 10^{6}$ leucócitos criopreservados em macrotubos, íntegros, descongelados e diluídos em $120 \mathrm{~mL}$ de solução salina. T3 - Leucócitos lisados - Infusão de 800 x $10^{6}$ leucócitos criopreservados em macrotubos, lisados, descongelados e diluídos em $120 \mathrm{~mL}$ de solução salina.

T4 - IL-8 - Infusão de 100 ng de Interleucina-8 criopreservada em macrotubos, descongelada e diluída em $120 \mathrm{~mL}$ de solução salina.
T5 - Controle - Infusão de meio R3F criopreservado em macrotubos, descongelado e diluído em $120 \mathrm{~mL}$ de solução salina.

Os tratamentos T2, T3, T4 e T5 foram identificados por diferentes cores (azul, vermelho, verde e preto) e armazenados em botijão de nitrogênio líquido. $\mathrm{O}$ executor não teve conhecimento, durante o desenrolar do experimento, da identificação dos diferentes tratamentos.

Os grupos de éguas eram diariamente examinados clinicamente e submetidos a exames bacteriológico [17] e citológico [15]. Os tratamentos foram repetidos diariamente por, no máximo, 4 dias, ou até a obtenção de um exame bacteriológico negativo. As éguas foram tratadas diariamente, por, no máximo, quatro dias, ou até que o exame bacteriológico não evidenciasse o crescimento de Streptococcus. No quinto dia após o aparecimento dos sinais clínicos, as éguas eram submetidas a novo exame histopatológico (amostra pós-infecção) e, no sétimo dia, todas as éguas eram tratadas com uma infusão intra-uterina de penicilina $G$ potássica cristalina, independente de terem eliminado a infecção ou não. Sete dias após, as éguas eram novamente submetidas a exame histopatológico e sincronizadas para realizar uma nova infecção e novo tratamento.

Todas as éguas foram submetidas a todos os tratamentos, perfazendo um total de 125 infecções experimentais. A Figura 1 mostra um esquema explicativo com as etapas do experimento.

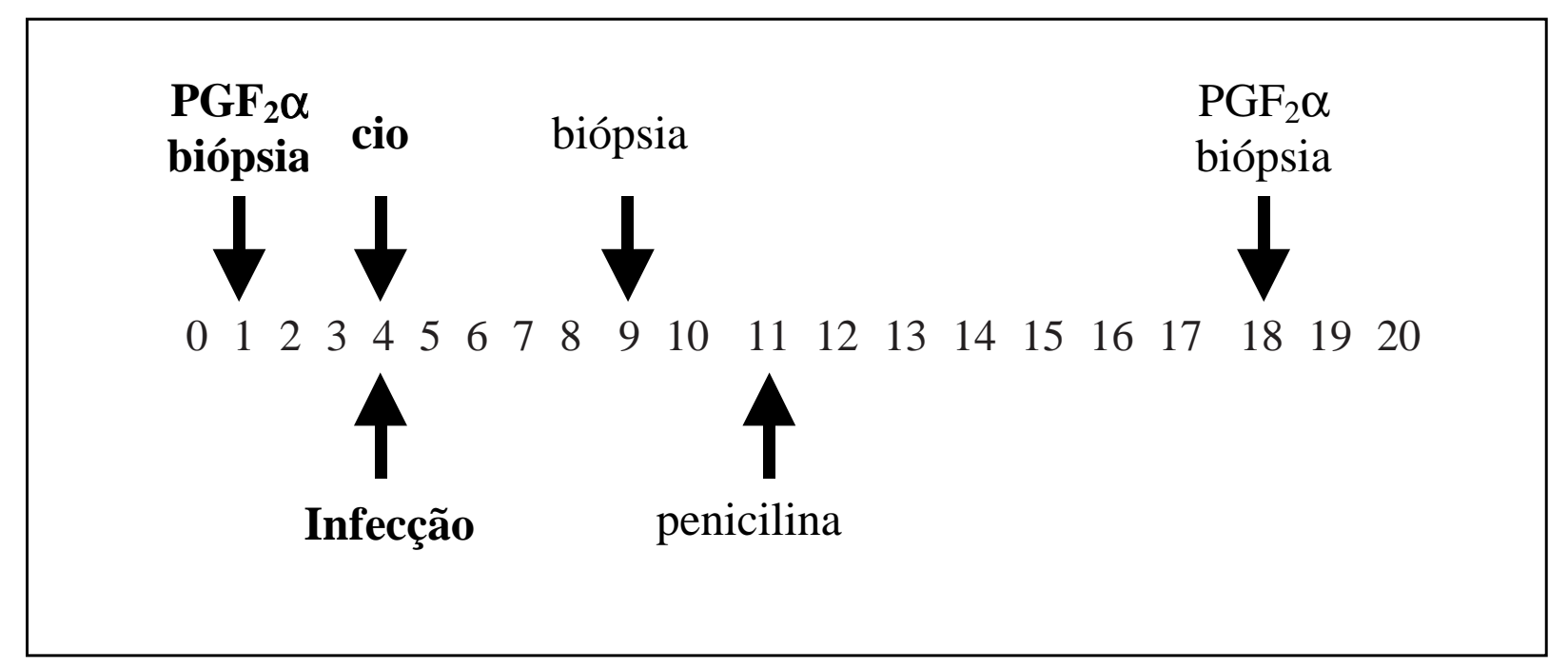

Figura 1. Esquema explicativo das etapas do experimento 


\section{Biópsias}

As biópsias uterinas foram coletadas com pinça tipo Yeoman e as amostras conservadas em formalina a $10 \%$. As biópsias foram embebidas em parafina após o procedimento padrão no Hypercenter $\mathrm{XP}^{4}$, seccionadas com micrótomo ${ }^{5}$ a 3-4 $\mu \mathrm{m}$ e coradas com hematoxilina - eosina. As amostras foram examinadas por microscopia óptica em aumento de 100,200 e 400 vezes.

Um total de 250 biópsias (10 biópsias por égua) foram avaliadas quanto ao efeito do tratamento para infecção experimental (biópsia pré e pós-infecção), com um total de 5 repetições.

As biópsias foram coletadas durante um período de 13 meses (fevereiro de 2001 a março de 2002), sendo que, no primeiro ano, foram avaliados os tratamentos da primeira e segunda infecções. No segundo ano foram avaliados os tratamentos da terceira, quarta e quinta infecções.

As amostras eram identificadas por números, não sendo conhecidos, durante sua avaliação, o nome da égua e o tratamento recebido.

Nas biópsias endometriais foram avaliados: 1) o epitélio luminal, quanto ao número de camadas, formato das células e presença de células inflamatórias; 2) os estratos compacto e esponjoso, quanto à presença de células inflamatórias; 3) os vasos, quanto à perivasculite. Nesta avaliação não foi levado em conta o grau de endometrose das éguas.

A classificação do grau de endometrite foi feita segundo Kenney e Doig [11], modificado por Schoon et al. [19]. Os graus de endometrite foram numerados de 0 a 3, conforme descrito na Tabela 1 .

\begin{tabular}{|c|c|}
\hline GRAUS & Classificação da endometrite \\
\hline $0-1$ & Sem inflamação \\
\hline $1-\| A$ & $\begin{array}{l}\text { LEVE a MODERADA infiltração inflamatória } \\
\text { difusa no estrato compacto; focos numerosos } \\
\text { disseminados no estrato compacto e esponjoso }\end{array}$ \\
\hline $2-\| B$ & $\begin{array}{l}\text { MODERADA difusa ou GRAVE } \\
\text { focal infiltração inflamatória }\end{array}$ \\
\hline $3-1 \mid I$ & GRAVE e difusa infiltração inflamatória. \\
\hline
\end{tabular}

A endometrite foi avaliada quanto à presença de neutrófilos, eosinófilos, linfócitos e plasmócitos. O grau de endometrite foi determinado pelo número de células por campo $(5 \mathrm{~mm})$ no estrato compacto e no estrato esponjoso. Como grau 1, foi classificado o endométrio com 0 a 15 células/campo; como grau 2, o endométrio com 15 a 30 células/campo; como grau 3, o endométrio com > 30 células/campo. Foram considerados graus intermediários $(1,5$ a 3,5) aqueles em que a endometrite abrangia o estrato esponjoso $(0,5$ grau a mais).

\section{Index}

Para verificação da influência dos tratamentos, foi criado um index com o objetivo de verificar se os neutrófilos, eosinófilos, plasmócitos e linfócitos variaram entre as biópsias efetuadas antes e após a infecção. Para tanto, determinou-se que o grau de inflamação provocada por cada tipo de célula fosse considerado 100 na biópsia pré-infecção. O index aumentava ou diminuía na razão de 10 pontos quando ocorria aumento ou diminuição de um nível no grau de endometrite para cada tipo de célula. Nos casos de aumento ou diminuição de meio grau, considerava-se uma variação de 5 pontos para mais ou para menos no index.

\section{Estatística}

Para a análise das médias dos tempos até a cura bacteriológica foi usado o procedimento GLM (Modelos Lineares Generalizados), do programa estatístico SAS (Statistical Analysis System) versão 6.12, considerando-se os efeitos das éguas, da categoria, seqüências dos grupos experimentais, do Quadrado Latino e dos tratamentos e suas interações. As comparações entre as médias dos tratamentos foram feitas pelo teste LSMeans (Least Square Means). Para a análise do index foi utilizada a análise de variância (procedimento GLM do SAS), em um modelo factorial com delineamento em blocos casualizados. As éguas foram consideradas como blocos. A variável resposta foi o index. Como fatores, foram testados os tratamentos, as células, a resistência e susceptibilidade.

\section{RESULTADOS}

As éguas susceptíveis e resistentes foram classificadas inicialmente, antes do experimento, quanto ao grau de alterações degenerativas e inflamatórias endometriais, segundo Kenney e Doig [11], modificado por Schoon et al. [19]. A classificação endometrial das éguas está expressa na Tabela 2. 
Tabela 2. Classificação histopatológica do endométrio das éguas susceptíveis e resistentes, segundo Kenney e Doig [11], modificado por Schoon et al.[19], conforme os graus de endometrite e endometrose

\begin{tabular}{ccc}
\hline Grau & Susceptiveis & Resistentes \\
\hline I & 4 & - \\
Ila & 10 & - \\
IIb & 6 & 2 \\
III & - & 3 \\
\hline
\end{tabular}

A maioria das éguas resistentes apresentou endométrio sem alteração $(n=4)$ ou com alterações leves $(n=10)$. As alterações moderadas foram observadas em 6 éguas resistentes. As éguas susceptíveis apresentaram apenas alterações moderadas $(n=2)$ e graves $(n=3)$.

A Tabela 3 mostra o tempo (em dias) necessários para que as éguas susceptíveis e resistentes eliminassem a bactéria após a infecção experimental com Streptococcus equi subsp. zooepidemicus.

Tabela 3. Número de dias de tratamento necessário para a eliminação da bactéria após infecção experimental nos diferentes grupos em éguas resistentes

\begin{tabular}{ccc}
\hline Tratamento & Resistentes (dias) & Susceptíveis (dias) \\
\hline Leucócitos frescos & $2,0 \pm 0,97 \mathrm{a}$ & $2,6 \pm 0,89 \mathrm{a}$ \\
Leucócitos congelados & $1,95 \pm 1,23 \mathrm{a}$ & $3,4 \pm 1,14 \mathrm{ab}$ \\
Interleucina-8 & $2,55 \pm 1,61 \mathrm{a}$ & $6,0 \pm 1,58 \mathrm{c}$ \\
Leucócitos lisados & $2,85 \pm 1,47 \mathrm{a}$ & $4,4 \pm 0,89 \mathrm{~b}$ \\
Controle & $2,7 \pm 1,41 \mathrm{a}$ & $6,2 \pm 2,05 \mathrm{c}$ \\
\hline
\end{tabular}

$\mathrm{a}(\mathrm{p}=0,1219)$ não houve diferença significativa $\mathrm{a}, \mathrm{b}, \mathrm{c}(\mathrm{p}=0,0001)$ letras diferentes indicam diferença significativa

Observa-se, na Tabela 3, que, nas éguas resistentes, não houve diferença significativa no número de dias para eliminação da bactéria entre os diferentes tratamentos. As éguas susceptíveis tratadas com interleucina-8 e o grupo controle levaram mais tempo para eliminar a bactéria quando comparados aos demais tratamentos e não diferiram entre si $(\mathrm{p}=0,8084)$. Os tratamentos leucócitos frescos e leucócitos congelados não apresentaram diferença significativa no tempo de eliminação da bactéria $(\mathrm{p}=0,3334)$. $\mathrm{O}$ tratamento leucócitos lisados diferiu significativamente de todos os demais tratamentos $(\mathrm{p}<0,05)$, exceto dos leucócitos congelados ( $\mathrm{p}=0,2274)$.

Na Figura 2 estão expressos os resultados obtidos nas biópsias pós-infecção, considerando-se a pre- dominância das células encontradas e o tempo de eliminação bacteriana das éguas resistentes e susceptíveis.

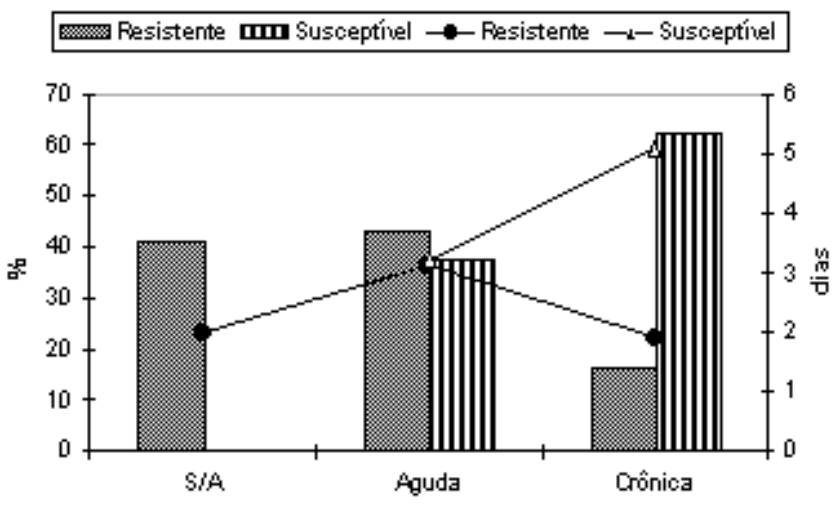

Figura 2. Tipo de endometrite (\%) observada na biópsia pós-infecção em éguas resistentes e susceptíveis, conforme a predominância das células encontradas e o tempo de eliminação bacteriana $(\bullet$ - resistentes, $\nabla$-susceptíveis). S/A sem alteração. Agudas - biópsias com predominância de neutrófilos e eosinófilos; crônicas - biópsias com predominância de plasmócitos e linfócitos

Observa-se, na Figura 2, que mais de 40\% das éguas resistentes não apresentaram alterações na biópsia e tiveram um tempo de eliminação bacteriana de 1,97 dia. Entretanto, nenhuma égua susceptível apresentou-se sem alteração. Endometrites agudas foram observadas em $43 \%$ das éguas resistentes e $37 \%$ das éguas susceptíveis e os tempos de eliminação do Streptococcus foi de 3,1 e 3,2 dias respectivamente. As endometrites com predominância de plasmócitos e linfócitos foram observadas em $16,1 \%$ das éguas resistentes e $62,5 \%$ das susceptíveis com tempos de eliminação bacteriana de 1,9 e 5,1 dias.

$\mathrm{O}$ index do número médio de neutrófilos das biópsias endometriais coletadas no $5^{\circ}$ dia pós-infecção das éguas resistentes e suscetíveis está expresso na Figura 3.

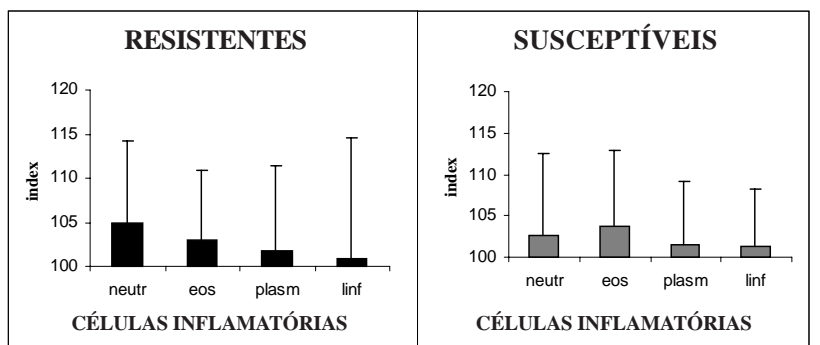

Figura 3. Index do número médio de neutrófilos, eosinófilos, plasmócitos e linfócitos observados nas biópsias no $5^{\circ}$ dia pós-infecção em éguas resistentes e susceptíveis 
Observou-se (Figura 3), nas éguas resistentes, uma neutrofilia $(\mathrm{p}<0,0001)$ e uma eosinofilia $(\mathrm{p}=0,0002)$ significativas nas biópsias do $5^{\circ}$ dia pósinfecção, quando comparadas com as biópsias préinfecção. $\mathrm{O}$ número de plasmócitos $(\mathrm{p}=0,0822)$ e linfócitos ( $p=04961)$ das biópsias pós-infecção não apresentou diferença significativa em relação às biópsias pré-infecção. Entretanto, nas éguas susceptíveis observou-se apenas uma eosinofilia significativa ( $\mathrm{p}=0,0498$ ) nas biópsias pós-infecção, quando comparadas às biópsias pré-infecção, não havendo diferença entre neutrófilos ( $\mathrm{p}=0,6731)$, plasmócitos $(\mathrm{p}=0,3552)$ e linfócitos $(\mathrm{p}=0,3833)$.

$\mathrm{O}$ index do número médio de neutrófilos das biópsias endometriais coletadas no $5^{\circ}$ dia pós-infecção em éguas resistentes e susceptíveis, conforme os diferentes tratamentos, está expresso na Figura 4. mento, o que não ocorreu nas éguas susceptíveis. As éguas resistentes, após 2 dias de tratamento, apresentaram index 102,1, significativamente inferior $(\mathrm{p}=0,0020)$ ao index 107,7 observado nas éguas tratadas por quatro dias.

$\mathrm{O}$ index do número médio de eosinófilos das biópsias endometriais coletadas no $5^{\circ}$ dia pós infecção, em éguas resistentes e suscetíveis, está expresso na Figura 6.

Na Figura 6, observa-se que o index do número de eosinófilos observado nas biópsias pós-infecção não se diferenciou significativamente entre os diferentes tratamentos nas éguas resistentes $(p=0,203)$ e susceptíveis ( $\mathrm{p}=0,5417)$. Entretanto, observou-se uma variação individual significativa entre as éguas resistentes ( $\mathrm{p}=0,0015)$, o que não ocorreu entre as éguas susceptíveis $(\mathrm{p}=0,5568)$.

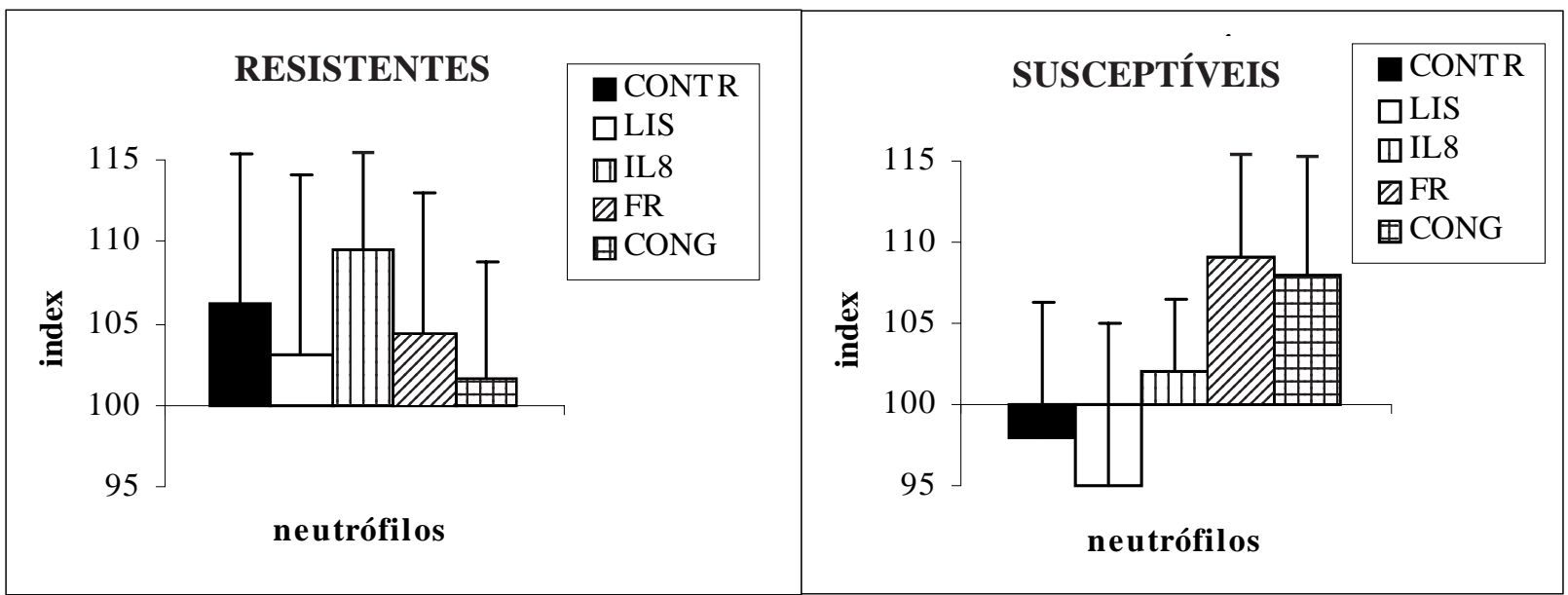

Figura 4. Index do número médio de neutrófilos das biópsias endometriais do $5^{\circ}$ dia pós-infecção em éguas suscetíveis e resistentes após diferentes tratamentos

Na Figura 4, observa-se que o index do número de neutrófilos observado nas biópsias pós-infecção não se diferenciou significativamente entre os diferentes tratamentos nas éguas resistentes $(\mathrm{p}=0,0633)$ e susceptíveis ( $\mathrm{p}=0,1782)$. Entretanto, observou-se uma variação individual significativa entre as éguas resistentes ( $\mathrm{p}=0,0134)$, o que não foi observado entre as éguas susceptíveis $(\mathrm{p}=0,6135)$.

O efeito do número de dias de tratamento sobre o index do número médio de neutrófilos nas biópsias no $5^{\circ}$ dia pós-infecção das éguas resistentes, está demonstrado na Figura 5.

Observa-se, na Figura 5, um aumento significativo ( $\mathrm{p}=0,0103$ ) do index de neutrófilos das éguas resistentes em relação ao número de dias de trata-

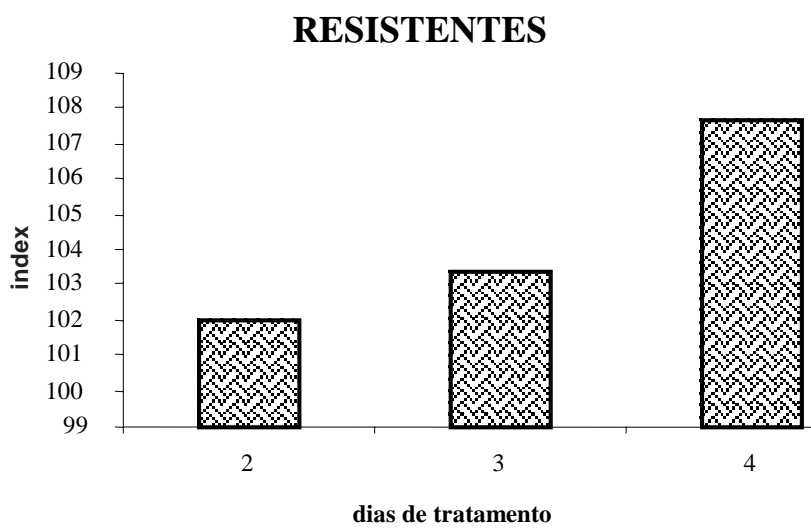

Figura 5. Index do número médio de neutrófilos com relação ao segundo, terceiro e quarto dia de tratamento, observado nas biópsias no $5^{\circ}$ dia pós-infecção das éguas resistentes 


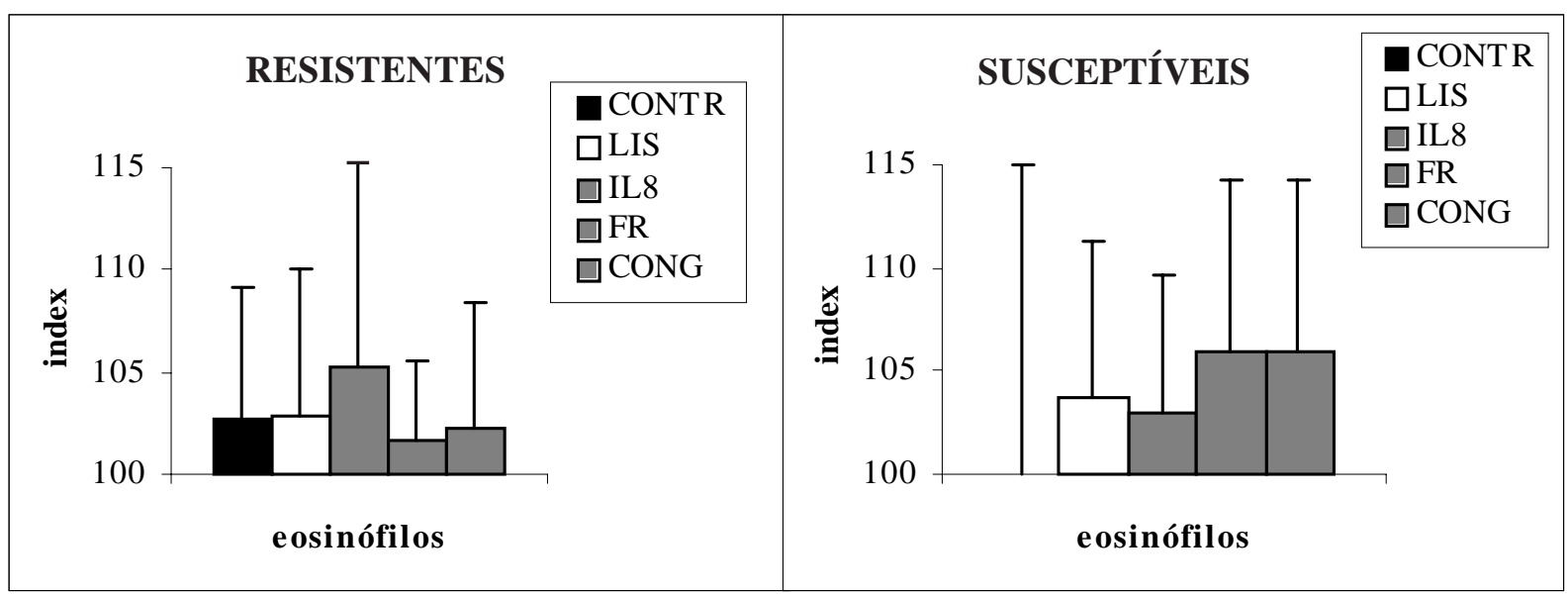

Figura 6. Média do número de eosinófilos das biópsias endometriais do $5^{\circ}$ dia pós-infecção nas éguas suscetíveis e resistentes, nos diferentes tratamentos

Não se observou influência dos tratamentos no index de plasmócitos, tanto nas éguas resistentes $(\mathrm{p}=0,202)$, como nas éguas susceptíveis $(\mathrm{p}=0,7851)$. Da mesma forma, não foi observada influência dos tratamentos no index de linfócitos nas resistentes $(\mathrm{p}=0,1019)$ e nas susceptíveis $(\mathrm{p}=0,7991)$.

\section{DISCUSSÃO}

Observou-se, nas éguas resistentes, neutrofilia e eosinofilia nas biópsias realizadas no $5^{\circ}$ dia pós-infecção, quando comparadas às biópsias pré-infecção. Nas éguas susceptíveis foi detectada somente eosinofilia, não se observando aumento do número de neutrófilos. Não houve aumento no número de linfócitos e plasmócitos nas biópsias pós-infecção, em relação às pré-infecção, nas éguas susceptíveis e resistentes.

A neutrofilia das éguas resistentes foi dependente do número de dias de tratamento, mas não foi influenciada pelo tipo de tratamento. O número de dias de tratamento era dependente da presença da bactéria no útero. Provavelmente, a neutrofilia observada nas éguas resistentes está relacionada à presença do antígeno, já que a migração de neutrófilos da corrente circulatória para os tecidos extravasculares é um importante processo na inflamação e a defesa é mediada principalmente pelos polimorfonucleados [24]. Entretanto, não foi observada neutrofilia nas éguas susceptíveis, mas observou-se que as éguas que eliminaram a bactéria mais rapidamente apresentaram um aumento do número de neutrófilos no quinto dia, o que não ocorreu nas éguas que permaneceram infectadas, nas quais predominaram os linfócitos e plasmócitos.

Neutrófilos uterinos de éguas susceptíveis, coletados 12 horas após a inoculação da bactéria, não apresentam resposta quimiotática nem deformabilidade [13]. Da mesma forma, foi observada uma menor capacidade migratória e fagocítica em neutrófilos uterinos de éguas susceptíveis [25].

Parece que as éguas susceptíveis, que reagiram apresentando uma endometrite aguda mais forte, conseguiram fazer a limpeza uterina mais rapidamente. Talvez, a baixa capacidade migratória e fagocítica dos neutrófilos das éguas susceptíveis tenha permitido a permanência do processo inflamatório, levando, posteriormente, a uma refratariedade no recrutamento de novos neutrófilos.

Os tratamentos nas éguas resistentes e susceptíveis não influenciaram a migração de neutrófilos no quinto dia, quando comparado com o número observado antes da infecção. Todos os tratamentos utilizados, com exceção do grupo controle, apresentavam efeito quimioatraente.

Nos tratamentos em que se utilizaram neutrófilos frescos e congelados, existia o efeito quimiotático dos próprios neutrófilos [7]. No tratamento com leucócitos frescos, houve a presença do plasma homólogo [1] na concentração de 60\% [18], com forte efeito quimiotático. No tratamento com leucócitos lisados, infundiam-se no útero restos celulares apresentando, segundo experimentos realizados previamente com câmaras quimiotáticas [18], bom efeito de atração. No tratamento com interleucina- 8 na concentração de $25 \mathrm{ng} / \mathrm{mL}$ infundia-se um potente quimioatraente [5,25].

Apesar de não se poder afirmar que não tenha ocorrido uma neutrofilia anterior ao quinto dia, provavelmente a eliminação bacteriana mais rápida apresentada pelas éguas susceptíveis tratadas com 
leucócitos frescos congelados e lisados não se deva aos fatores quimioatraentes infundidos.

É possível que a ausência de quimiotaxia observada no $5^{\circ}$ dia pós-infecção pelas éguas tratadas com interleucina-8 se deva à dose utilizada. Bons resultados de quimiotaxia in vitro de leucócitos coletados do útero foram observados após uma infusão de uma dose total de $1250 \mathrm{ng}$ de interleucina- 8 em um volume de $50 \mathrm{~mL}$ de PBS [25]. No presente estudo, foi utilizada uma dose total de $100 \mathrm{ng}$ de interleucina-8, diluída em $120 \mathrm{~mL}$ de $\mathrm{NaCl}$. É possível que, com uma dose maior de interleucina-8, obtivéssemos resultados diferentes quanto à presença de neutrófilos no endométrio.

A eosinofilia teve variação individual significativa entre as éguas resistentes e susceptíveis, e não foi influenciada pelos dias de tratamento. Raramente foi observada uma endometrite apenas eosinofílica. $\mathrm{Na}$ maioria das vezes, os eosinófilos apareciam junto com os neutrófilos e, mais raramente, com linfócitos e plasmócitos.

Blüthgen [2] também observou um aumento no número de eosinófilos em éguas com endometrite purulenta e, quanto maior o grau da endometrite, maior o número de eosinófilos. Por outro lado, o autor não observou eosinófilos nas endometrites não purulentas moderadas e graves. O aparecimento de eosinófilos no endométrio da égua não está ainda totalmente esclarecido e parece estar relacionado com uma sensibilidade individual [20].

Os eosinófilos são parte integrante do sistema de defesa da mucosa endometrial contra organismos invasores e produzem moléculas como prostaglandinas, leucotrienos e citoquinas, que amplificam a resposta inflamatória, recrutando e ativando mais eosinófilos, neutrófilos e células epiteliais [9]. A presença de eosinófilos no útero sofre também influência hormonal. Durante o ciclo estral de éguas sadias, foram encontrados mais eosinófilos no endométrio durante a fase estrogênica [2].

É possível que a eosinofilia encontrada no presente trabalho seja consequiência da influência do estrogênio, já que as biópsias pós-infecção eram coletadas ainda durante o estro.

\section{CONCLUSÃO}

Conclui-se que éguas susceptíveis à endometrite, com presença de Streptococcus no útero, não apresentam neutrofilia cinco dias após a infecção. Provavelmente, o menor tempo de eliminação bacteriana observada após tratamento com leucócitos frescos e congelados deva-se a outros fatores que não a quimioatração exercida por essas células.

\section{Notas Informativas}

${ }^{1}$ Liquemine- Roche S.A.- São Paulo -SP

${ }^{2}$ Dextrosol- Refinações de Milho, Brasil - Itatiaia - RJ

${ }^{3}$ Human IL-8, Bio-Concept GmbH- Umkirch, Alemanha

${ }^{4}$ Biochrom - Berlin, Alemanha

${ }^{5}$ Shandon - Frankfurt, Alemanha

${ }^{6}$ Reichert-Jung, Austria

\section{REFERÊNCIAS}

1 Asbury A.C. 1984. Uterine defense mechanisms in the mare: the use of plasma in the management of endometritis. Theriogenology. 21:387-393.

2 Blüthgen, U. 2001. Untersuchungen zu Vorkommen, Nachweis und Bedeutung von Eosinophilen Granulozyten im Endometrium der Stute unter besonderer Berücksichtigung des Vorkommens von Sprosspilzen. Tese (Doutorado em Medicina Veterinária), Faculdade de Medicina Veterinária de Leipzig, Alemanha.

3 Castilho L.F.F., Zerbe H., Rabe U., Leibold W. \& Klug E. 1997. Isolierung und Gefrierkonservierung von immunokompetenten polymorphkernigen neutrophilen Granuloziten zur Endometritisbehandlung beim Pferd. Pferdeheilkunde. 13:437-444.

4 Doig P. A. \& Waelchli R.O.1993. Endometrial biopsy. In: Mckinnon A.O. \& Voss J.L. (Eds). Equine Reproduction. Philadelphia: Lea \& Febiger, pp. 225-233.

5 Engelke F., Zerbe H., Klug E. \& Leibold W. 1999. A new model system for endometritis in mares - preliminary results. Pferdeheilkunde. 15: 579-583.

6 Farrely B.T. \& Mullaney M.A.1964. Cervical and uterine infection in Thoroughbred mares. Irish Veterinary Journal. 18:201-212. 
7 Faurschou M. \& Borregaard N. 2003. Neutrophil granules and secretory vesicles in inflamation. Microbes and Infection. 5: 1317-1327.

8 Hughes J.P. \& Loy R.G. 1975. The relation of infection to infertility in the mare and stallion. Equine Veterinary Journal. 7: $155-159$.

9 Janeway C.A., Travers P. \& Walport M. 1999. Allergy and Hypersensitivity. In: Immunobiology: the immune system in health and disease. 4th. edn. London: Current Biology Publications, pp.1-24.

10 Kenney R.M. 1975. Prognostic value of endometrial biopsy of the mare. Journal of Reproduction and Fertility. (Suppl 23): 347-348.

11 Kenney R.M. \& Doig P.A.1986. Equine endometrial biopsy. In: Morrow D.A. (Ed). Current Therapy in Theriogenology. Philadelphia: W.B. Saunders, pp.723-729.

12 LeBlanc M.M., Neuwirth L., Asbury A.C., Tran T., Mauragis D. \& Klapstein E. 1994. Scintigraphic measurements of uterine clearance in normal mares and mares with recurrent endometritis. Equine Veterinary Journal. 26: 109-113.

13 Liu I.K.M., Cheung A.T.W., Walsh E.M., Miller M.E. \& Lindenberg P.M. 1985. Comparison of peripheral blood and uterine-derived polymorphonuclear leucocytes from mares resistant and susceptible to endometritis: chemotactic and cell elastimetry analysis. American Journal of Veterinary Research.46: 917-920.

14 Mattos R.C., Castilho L.F.F., Malschitzky E., Mattos R. \& Gregory R.M. 1999. Treatment of endometritis of experimentally infected mares: I - effect of lavage, plasma and leucocytes on uterine bacterial clearance. Arquivos da Faculdade de Veterinária da UFRGS. 27: 49-60.

15 Mattos R.C., Mattos A.L.G., Günzel A.R. \& Klug E. 1984. Citologia endometrial na égua como método de diagnóstico auxiliar e complementar. Revista Brasileira de Reprodução Animal. 8: 83-90.

16 Mattos R.C., Neves A.P., Gregory R.M., Gomes M.J.S., Mattos R., Meirelles L.S., Lagares M.A., Keller A., Wald V.B., Vieira M.J. \& Hött A.K. 1999. Treatment of endometritis of experimentally infected mares: II - effect of ecbolic drugs and plasma enriched with leucocytes on uterine bacterial clearance. Arquivos da Faculdade de Veterinária da UFRGS. 27: 61-72.

17 Merkt H. \& Von Leppel J.F. 1970. Die Entnahme von proben für die bakteriologische Untersuchung des Genitalsekretes der Stute, ihre Beurteilung sowie Behandlungshinweise. Deutsches Tierärztliche Wochenschrift. 77: 489-528.

18 Neves A.P., Keller A., Engelke F., Zerbe H., Leibold W., Klug, E., Schoon H.A. \& Mattos R.C. 2005. Evaluation of chemotaxis, vitality and generation of reactive oxygen species (ROS) of fresh, frozen and lysed equine leukocytes. Revista Brasileira de Reprodução Animal submetido para publicação.

19Schoon H.A, Schoon D. \& Klug E. 1992. Uterusbiopsien als Hilfsmittel für Diagnose und Prognose von Fertilitätsstörungen der Stute. Pferdeheilkunde. 8: 355-362.

20 Schoon H.A., Schoon D. \& Klug E. 1997. Die Endometrium biopsie bei der Stute im klinisch-gynäkologischen Kontext. Pferdeheilkunde. 13: 453-464.

21 Troedsson M.H.T., Liu I.K.M., Ing M., Pascoe J. \& Thurmond M.J. 1993. Multiple site electromyographic recordings of uterine activity following an intrauterine bacterial challenge in mares susceptible and resistant to chronic uterine infection. Journal of Reproduction and Fertility. 99: 307-313.

22 Troedsson M.H.T., Liu I.K.M. \& Thurmond M. 1993. Function of Uterine and Blood-Derived Polymorphonuclear Neutrophils in Mares Susceptible and Resistant to Chronic Uterine Infection: Phagocytosis and Chemotaxis. Biology of Reproduction. 49: 507-514.

23 Watson E.D. 1988. Uterine defence mechanisms in mares resistant and susceptible to persistent endometritis: A review. Equine Veterinary Journal. 20: 397-400.

24 Watson E.D., Stokes C.R. \& Bourne F.J. 1987. Cellular and humoral defence mechanisms in mares susceptible and resistant to persistent endometritis. Veterinary Immunology and Immunopathology. 16: 107-121.

25 Zerbe H., Schuberth H.J., Engelke F., Frank J., Klug E. \& Leibold W. 2003. Development and comparison of in vivo and in vitro models for endometritis in cows and mares. Theriogenology. 60: 209-223.

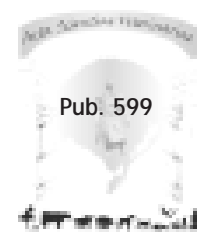

